\title{
SERUM ADROPIN LEVEL AND KIDNEY FUNCTIONS IN TYPE-II DIABETIC RAT MODEL WITH AND WITHOUT PIOGLITAZONE TREATMENT
}

\author{
By \\ Ebtesam M. Ibrahim and Suzan M.M. Moursi \\ Physiology Department, Faculty of Medicine, Zagazig University, Egypt
}

\begin{abstract}
Background: Diabetic nephropathy (DN) is the most common cause of end stage renal disease (ESRD), and the leading cause of death in diabetic patients. Treatment with thiazolidinediones, particularly pioglitazone, may ameliorate kidney deterioration. Moreover, several peptide hormones participate in maintaining metabolic homeostasis including the recently discovered adropin. Data regarding adropin-circulating levels in type II diabetes mellitus (T2DM) are still conflicting.
\end{abstract}

Objective: This study was designed to determine pioglitazone effect on some metabolic and kidney function parameters in type II diabetic rat model, and to investigate the relationship between serum adropin and such parameters.

Materials and methods: Thirty healthy adult male albino rats were used for this study. The rats were randomly and equally divided into three groups. Group-1; control group, group-2; type II diabetic group, and group-3; pioglitazone- treated diabetic group. Rats were examined for body weight, body mass index (BMI), adropin, glucose \& insulin, insulin resistance (HOMA-IR), lipids profile, inflammatory cytokines [interleukin-6 (IL-6), tumor necrosis factor-alpha (TNF- $\alpha$ ), plasminogen activator inhibitor-1 (PAI-1)], serum urea, creatinine, uric acid, angiotensin II, mean arterial blood pressure (MABP), urine flow rate, protein, creatinine, glomerular filtration rate (GFR), renal malondialdhyde (MDA) level, glutathione peroxidase (GSH-Px), and superoxide dismutase (SOD) activities. Histopathological examinations for kidney tissues were also done.

Results: The present study revealed that diabetic rats showed significantly lower serum adropin levels than controls. Diabetes also significantly increased serum glucose with insulin resistance, serum total cholesterol (TC), triglyceride (TG), low density lipoprotein-cholesterol (LDL-c), very low density lipoproteincholesterol (VLDL-c), serum IL-6, TNF- $\alpha$, PAI-1, serum urea, creatinine, uric acid, angiotensin II , MABP, urine flow rate, protein and renal MDA [with significant negative correlation versus serum adropin] but significantly decreased serum insulin and high density lipoprotein-cholesterol (HDL-c), urine creatinine, GFR and renal SOD \& GSH-Px activities [with significant positive correlation versus serum adropin] together with deterioration of kidney histoarchitecture. Moreover, pioglitazon treatment resulted in a significant recovery in the above mentioned parameters in the treated diabetic group.

Conclusion: Serum adropin concentration was negatively associated with the observed renal deterioration and may have a potential protective role, in addition to pioglitazone ameliorating effects, in diabetic nephropathy.

Key words: Diabetes, nephropathy, pioglitazone, adropin. 


\section{EBTESAM M. IBRAHIM and SUZAN M.M. MOURSI}

\section{INTRODUCTION}

Diabetes is the most common cause of progressive kidney failure (nephropathy) that is reported to develop in $30-40 \%$ of patients with diabetes, and has become a leading cause of end stage renal failure worldwide (Tanios and Ziyadeh, 2012). Diabetic nephropathy is characterized by structural as well as functional abnormalities (Forbes et al., 2008).

The fundamental mechanisms responsible for nephropathy in diabetes involves tubulointerstitial fibrosis and glomerulosclerosis caused by hyperglycemia, hyperlipidemia, hypertension, oxidative stress, aldosterone-reninangiotensin system activation, inflammation and release of profibrotic factors such as transforming growth factor $\beta 1 \&$ PAI-1 (Qian et al., 2008 and Sarafidis, 2008).

Currently available treatment options can only delay DN progression or turn to renal replacement therapies. Therefore, it is urgent to identify novel biomarkers for early diagnosis and to develop some effective treatment strategies for patients at high risk (Hu and Chen, 2016).

Thiazolidinediones [peroxisome proliferator-activated receptor- $\gamma$ (PPAR- $\gamma$ ) agonists] in general, and pioglitazone in particular, reduce blood pressure and exert pleiotropic effects beyond glucose lowering in the human (Abe et al., 2008). In addition, adropin (ADR) is a new peptide metabolic hormone; 76 amino acid; expressed in the brain, liver, pancreas and kidney_tissues, and has been shown to regulate energy homeostasis (Kumar et al., 2008 and Aydin et al., 2013). However, literature information showing the relationship between adropin and T2DM is very limited although it can be an emerging diagnostic marker for diagnosis of T2DM (Akcilar et al., 2016 and Hosseini et al., 2016).

There are apparently contradictory reports concerning adropin-circulating levels in T2DM. Hosseini et al. (2016) reported higher adropin levels; meanwhile, others reported lower levels (Butler et al., 2012 and Wu et al., 2014) in T2DM patients. Kumar et al. (2008) have also found an association between adropin deficiency, increased adiposity and insulin resistance that could, therefore, be a factor regulating glucose and lipid homeostasis and can protect against the hepatosteatosis and hyperinsulinemia associated with obesity.

Therefore, we designed this study to examine the renal functions in type II diabetic rat model treated with pioglitazone, and identify the possible mechanisms of action in relation to serum adropin level.

\section{MATERIALS AND METHODS}

Thirty healthy adult male wistar albino rats weighing 182-212 $\mathrm{g}$ were obtained from the animal house of Faculty of Veterinary Medicine- Zagazig University. Rats were kept in steel wire cages $(70 \mathrm{~cm} \mathrm{x}$ $50 \mathrm{~cm}$ x $30 \mathrm{~cm}-5 \mathrm{rats} / \mathrm{cage})$ under hygienic conditions. They were fed the commercial rodent chow with free access to water, kept at room temperature and were maintained on a normal light/dark cycle. Rats were adapted to the new environment for one week before the experiment going on. The animal experiments were approved by the Institutional Research Board. 
Rats were randomly divided into three equal groups:

Group-1 [normal control group]: in which rats were fed normal chow diet for 13 weeks.

Group-2 [Type 2 diabetic group rats]: in which rats were fed high fat diet (HFD) (60.3\% of energy derived from fat, $18.4 \%$ from protein, and $21.3 \%$ from carbohydrates; $5.1 \mathrm{kcal} / \mathrm{g}$ ) for 5 weeks, then the HFD was replaced with standard rodent diet and animals received single intraperitoneal injection of low dose of streptozotocin (STZ) (Sigma Aldrich Co.USA) (35 mg/kg BW) dissolved in normal saline (Danda et al., 2005). Plasma glucose level was checked after 7 days of STZ injection. Rats with plasma glucose levels of $\geq 250 \mathrm{mg} / \mathrm{dl}$ were included into the study for subsequent 13 weeks (Zhang et al., 2017).

Group-3 [Type 2 diabetic rats treated with pioglitazone]: Diabetic rats were given 12 $\mathrm{mg} / \mathrm{kg} /$ day of pioglitazone HCL (ACTOS 30 mg tablets, Arab Pharmaceutical Manufacturing Co. Ltd, Sult - Jordan) in the chow for 13 weeks (Toblli et al., 2009).

\section{Anthropometric measures:}

Measurement of body weight and length: Each rat was put in closed plastic container and was weighed at the first and the last day of the experiment. The results were written in a record for each rat.

Body length was taken as the distance from the nose tip to the anus at the start and the end of experiment (Novelli et al., 2007).
Calculation of Body Mass Index [BMI]:

$\mathrm{BMI}=$ body weight $(\mathrm{gm}) /$ length ${ }^{2}\left(\mathrm{~cm}^{2}\right)$.

(Novelli et al., 2007).

Measurement of MABP pressure: MABP is measured in millimeters of mercury $(\mathrm{mm} \mathrm{Hg})$ by non invasive blood pressure monitor (NIBP 250, Serial No: 21202-108, BIOPAC system, Inc.; USA) (Abubakar et al., 2015).

Urine collection: Urine samples were collected for 24 hours by metabolic cages, measured for volume and centrifuged 10 minutes at approximately $3000 \mathrm{rpm}$ to remove insoluble materials. The supernatant was kept at $-20^{\circ} \mathrm{C}$ for further analysis (Jones et al., 1973).

Measurement of urine total proteins: It was carried out as described by Nishi and Elin (1985) using urinary protein assay kit [Chondrex, Inc. 2607-151 place NE Redmond, WA 98052, USA].

Measurement of urine Creatinine: It was carried out as described by Jaffé (1986) using Creatinine (Colorimetric) kit [Vitro Scient, Inshas Industrial Zone, Belbis, Sharkia Egypt].

Blood sampling: Retro-orbital venous plexus blood samples were obtained then serum was separated by allowing the blood samples to clot then centrifuged at $3000 \mathrm{rpm}$ for 20 minutes, kept at $-20^{\circ} \mathrm{C}$ and used to measure the serum levels of adropin, glucose, insulin, lipids profile, IL-6, TNF- $\alpha$, PAI-1, serum urea, creatinine, uric acid and angiotensin II.

Measurement of serum adropin: Adropine was analyzed with rat adropine ELISA kit (Sun Red Biotechnology, 
China- Catalogue No 201-11-3361) according to Yang et al. (2016).

Measurement of serum glucose and insulin: Serum glucose was estimated as described by Tietz (1995) using specific glucosekit (Bioscience, Egypt) and analyzed by spectrophotometers device (URIT-810, China). Insulin was measured by enzyme amplified sensitivity immunoassay (EASIA) as described by Temple et al. (1992) using specific insulin kit (BioSource Belgium) and analyzed by spectrophotometers device.

Calculation of Insulin resistance (HOMA-IR): Homeostasis model assessment of insulin resistance (HOMA-IR) was calculated according to the following formula [HOMA-IR $=$ insulin $(\mu \mathrm{U} / \mathrm{mL}) \mathrm{x}$ glucose (mg/dl) /405] (Matthews et al., 1985).

Measurement of serum lipids profile: Total cholesterol (TC) and triglycerides (TG) were measured by enzymatic colorimetric method described by Tietz (1995) using specific cholesterol and triglycerides kits (Spinreact Spain), and analyzed by spectrophotometers device. High density lipoprotein-cholesterol (HDL-c) was measured by precipitating reagent method described by Tietz (1995) using HDLc precipitating reagent kit (Spinreact, Spain), and analyzed by spectrophotometers device. Low density lipoprotein-cholesterol (LDL-c) and very low density lipoprotein-cholesterol (VLDL-c) were estimated by using Friedewald et al. (1972) formula.

$$
\text { LDLc }=\mathrm{TC}-\mathrm{HDLc}-\left(\frac{\mathrm{TG}}{5}\right) \quad \text { VLDLc }=\frac{\mathrm{TG}}{5}
$$

Measurement of serum creatinine: It was carried out as described by Jaffé (1986) using Creatinine (Colorimetric) kit [Vitro Scient, Inshas Industrial Zone, Belbis, Sharkia Egypt].

Measurement of serum urea: It was carried out as described by Tietz (1990) using urea/bun (urease) kit [Vitro Scient, Inshas Industrial Zone, Belbis, Sharkia Egypt].

Measurement of serum uric acid: It was carried out as described by Barham and Trinder (1972) using uric acid (uricase/peroxidase) kit: [BioSystems S.A. Quality System certified according to EN ISO 13485 and EN ISO 9001 standards Costa Brava, 30. 08030 Barcelona, Spain].

Measurement of Glomerular filtration rate (GFR): By using creatinine clearance formula (Cockcroft and Gault, 1976).

$$
\text { GFR }[\text { Creatinine clearance }](\mathrm{m} / \mathrm{min})=\frac{\text { Urine creatinine } X \text { Urine volume }}{\text { Serum creatinine } \mathrm{X}_{1440}}
$$

Measurement of serum angiotensin II: It was carried out as described by Kumar et al. (2016) using rat angiotensin II enzyme immunoassay (EIA) kit (Catalog Number EK-002-12; Phoenix Pharmaceutical Inc., Burlingame, CA).

Measurement of serum TNF- $\alpha$ level: It was carried out as described by Fernando et al. (1998), using commercial ELISA kit, (Catalog Number RAB0480, provided by Sigma-Aldrich Co).

Measurement of serum IL-6 and PAI-1 levels were carried out as described by Engvall and Perlmann (1971), using IL6 ELISA Kit (Catalog Number RAB0306 provided by Sigma-Aldrich Co) and PAI- 
1 ELISA Kit (serial No. 201-11-0637, Sunred biological technology, Shanghai, China].

Tissue sampling and histopathological examination: Immediately after collecting blood samples, rats were killed by decapitation after light ether anesthesia. Kidneys were immediately excised, the left one was processed for histopathological studies and the right one was homogenated for biochemical estimations of levels of MDA, SOD, and GSH-Px activities.

Renal antioxidant system evaluation: Tissue homogenates were prepared as described by Zhang et al. (2017).

Assay of MDA level was according to the method described by Ohkawa et al. (1979).

Assay of superoxide dismutase (SOD) activity was according to the method described by Kakkar et al. (1984).

Assay of glutathione peroxidase (GSHPx) activity: according to the method described by Reddy et al. (1995).

Histopathological examination kidneys were rinsed with ice-cold normal saline $\left(4^{\circ} \mathrm{C}\right)$ to exclude the blood cells, blotted and dried with filter paper, then tissue portions from kidneys were kept in $10 \%$ buffered formalin - saline at $4^{\circ} \mathrm{C}$ for at least one week (1ry fixation), then the specimens were dehydrated with a series of ascending grade of ethanol from 75 to $100 \%$. Tissues were placed thereafter in xylol and embedded in paraffin wax. Cross sections of about 1-2 $\mu \mathrm{m}$ thickness of kidney was processed on slides and stained with haematoxylin and eosin $(\mathrm{H} \&$
E) stain to study general microscopic characters of the kidney for routine light microscope assessment at magnification power [400 ] (Drury and Wallington, 1980).

\section{Statistical Analysis:}

Results were presented as mean \pm SD and analyzed using version 18 SPSS program (SPSS Inc. Chicago, IL, USA). One way Analysis of variance (ANOVA) was used followed by student- least significant differences (LSD) test to compare statistical differences between groups. Paired t. test was used to compare the initial and final body weights. Pearsons test was done to detect correlations between parameters. $\mathrm{P}$ value less than 0.05 was considered to be significant.

\section{RESULTS}

The present study showed that HFD/STZ significantly increased serum glucose, HOMA-IR, serum TC, TG, LDLc, VLDL-c, inflammatory cytokines (IL-6, TNF- $\alpha$ \& PAI-1), serum creatinine, urea, uric acid, angiotensin II , urine flow rate and total urine protein, MABP, renal MDA levels. It significantly decreased final body weight, BMI, serum adropin, insulin, HDL-c levels, urine creatinine level, GFR and renal SOD, and GSH-Px activities in the diabetic group when compared to control (Tables 1-4 and photos 1-3).

However, It was found that pioglitazone treatment significantly decreased serum glucose, HOMA-IR, serum TC, TG, LDL-c, VLDL-c, inflammatory cytokines (IL-6, TNF- $\alpha$ \& PAI-1), serum creatinine, uric acid, urea and angiotensin II, urine 
flow rate, total urine protein, MABP, renal MDA levels. It significantly increased final body weight, BMI, serum adropin, HDL-c level, urine creatinine, GFR, renal SOD, and GSH-Px activities, with no significant change in serum insulin level in the treated diabetic group when compared to untreated diabetic one (Tables 1-4 and photos 1-3).

Moreover, there were significant negative correlations between serum adropin, serum glucose, HOMA-IR, serum TC, TG, LDL-c, VLDL-c, serum urea, uric acid, angiotensin II, urine flow rate, total urine protein, MABP and renal
MDA, but there were significant positive correlations between serum adropin, BMI, serum insulin, HDL-c, urine creatinine, GFR, renal SOD, GSH-Px activities in both diabetic and pioglitazone treated diabetic groups.

In addition, histopathological examination in the present study revealed severe damage to the kidney tissue including distorted renal glomeruli, vacuolated renal tubular cells, interstitial hemorrhage and severe cellular infiltration; in the diabetic group that was ameliorated by pioglitazone treatment in the treated diabetic group (photos 4-6).

Table (1): Body weights, serum adropin and final BMI of all studied groups

\begin{tabular}{|c|c|c|c|c|}
\hline \multicolumn{2}{|c|}{ Parameters $\quad$ Groups } & Group -1 & Group -2 & Group -3 \\
\hline \multirow{2}{*}{$\begin{array}{l}\text { Initial body } \\
\text { weight }(\mathrm{g})\end{array}$} & $\bar{X} \pm S D$ & $198.6 \pm 8.44$ & $196.8 \pm 10.03$ & $197.6 \pm 9.67$ \\
\hline & $\mathrm{P}$ value of LSD & & $\mathrm{NS}^{\mathrm{a}}$ & $\mathrm{NS}^{\mathrm{b}}$ \\
\hline \multirow{3}{*}{$\begin{array}{l}\text { Final body } \\
\text { weight }(\mathrm{g})\end{array}$} & $\bar{X} \pm S D$ & $279.8 \pm 11.24$ & $180.6 \pm 7.05$ & $208.2 \pm 7 . \vee 88$ \\
\hline & $\mathrm{P}$ value of LSD & & $\mathrm{P}<0.001^{\mathrm{a}}$ & $\mathrm{P}<0.001^{\mathrm{a}, \mathrm{b}}$ \\
\hline & $\begin{array}{l}\mathrm{P} \text { value of } \mathrm{t} \text { test between } \\
\text { initial and final body } \\
\text { weights }\end{array}$ & $\mathrm{P}<0.001$ & $\mathrm{P}<0.01$ & NS \\
\hline \multirow{2}{*}{$\begin{array}{l}\text { Serum } \\
\text { adropin } \\
(\mathrm{ng} / \mathrm{ml})\end{array}$} & $\bar{X} \pm S D$ & $37.9 \pm 4.48$ & $26 \pm 4.37$ & $31.1 \pm 2.13$ \\
\hline & $P$ value of LSD & & $\mathrm{P}<0.001^{\mathrm{a}}$ & $\mathrm{P}<0.001^{\mathrm{a}}, \mathrm{P}<0.01^{\mathrm{b}}$ \\
\hline \multirow{3}{*}{$\begin{array}{l}\text { Final BMI } \\
\left(\mathrm{g} / \mathrm{cm}^{2}\right)\end{array}$} & $\bar{X} \pm S D$ & $0.56 \pm 0.05$ & $0.35 \pm 0.02$ & $0.40 \pm 0.02$ \\
\hline & $P$ value of LSD & & $\mathrm{P}<0.001^{\mathrm{a}}$ & $\mathrm{P}<0.001^{\mathrm{a}}, \mathrm{P}<0.05^{\mathrm{b}}$ \\
\hline & r with serum adropin & & $r=0.765, P<0.05$ & $\mathrm{r}=0.740, \mathrm{P}<0.05$ \\
\hline
\end{tabular}

$a=$ versus group $-1 \quad b=$ versus group-2 
SERUM ADROPIN LEVEL AND KIDNEY FUNCTIONS IN TYPE-II DIABETIC... 115

Table (2): Serum glucose, insulin, HOMA-IR, serum cholesterol, triglyceride, HDL-c, LDL$\mathrm{c}$ and VLDL-c of all studied groups.

\begin{tabular}{|c|c|c|c|c|}
\hline \multicolumn{2}{|c|}{ Parameters $\quad$ Groups } & Group I & Group II & Group III \\
\hline \multirow{3}{*}{$\begin{array}{l}\text { Serum glucose } \\
(\mathrm{mg} / \mathrm{dl})\end{array}$} & $\bar{X} \pm S D$ & $84.83 \pm 5.92$ & $314.16 \pm 42.98$ & $190.7 \pm 20.30$ \\
\hline & P value of LSD & & $\mathrm{P}<0.001^{\mathrm{a}}$ & $\mathrm{P}<0.001^{\mathrm{a}, \mathrm{b}}$ \\
\hline & $\begin{array}{l}\mathrm{r} \text { with serum } \\
\text { adropin }\end{array}$ & & $\mathrm{r}=-0.979, \mathrm{P}<0.001$ & $\mathrm{r}=-0.977, \mathrm{P}<0.001$ \\
\hline \multirow{3}{*}{$\begin{array}{l}\text { Serum insulin } \\
\quad(? \mathrm{IU} / \mathrm{ml})\end{array}$} & $\bar{X} \pm \mathrm{SD}$ & $21.121 \pm 2.25$ & $18.232 \pm 1.62$ & $18.61 \pm 1.31$ \\
\hline & P value of LSD & & $\mathrm{P}<0.01^{\mathrm{a}}$ & $\mathrm{P}<0.01^{\mathrm{a}}, \quad \mathrm{NS} \mathrm{S}^{\mathrm{b}}$ \\
\hline & $\begin{array}{l}\mathrm{r} \text { with serum } \\
\text { adropin }\end{array}$ & & $r=0.640, P<0.05$ & $r=0.636, P<0.05$ \\
\hline \multirow{3}{*}{ HOMA-IR } & $\bar{X} \pm S D$ & $4.41 \pm 0.49$ & $14.04 \pm 1.59$ & $8.73 \pm 0.79$ \\
\hline & P value of LSD & & $\mathrm{P}<0.001^{\mathrm{a}}$ & $\mathrm{P}<0.001^{\mathrm{a}, \mathrm{b}}$ \\
\hline & $\begin{array}{l}\mathrm{r} \text { with serum } \\
\text { adropin }\end{array}$ & & $\mathrm{r}=-0.663, \mathrm{P}<0.05$ & $r=-0.63\urcorner, P<0.05$ \\
\hline \multirow{3}{*}{$\begin{array}{l}\text { Serum cholesterol } \\
(\mathrm{mg} / \mathrm{dl})\end{array}$} & $\bar{X} \pm S D$ & $75.586 \pm 5.49$ & $170.44 \pm 13.08$ & $112 \pm 11.96$ \\
\hline & P value of LSD & & $\mathrm{P}<0.001^{\mathrm{a}}$ & $\mathrm{P}<0.001^{\mathrm{a}, \mathrm{b}}$ \\
\hline & $\begin{array}{l}\mathrm{r} \text { with serum } \\
\text { adropin }\end{array}$ & & $\mathrm{r}=-0.940, \mathrm{P}<0.001$ & $r=-0.677, P<0.05$ \\
\hline \multirow{3}{*}{$\begin{array}{l}\text { Serum triglyceride } \\
(\mathrm{mg} / \mathrm{dl})\end{array}$} & $\bar{X} \pm S D$ & $64.59 \pm 8.82$ & $144.60 \pm 12.39$ & $95.24 \pm 8.21$ \\
\hline & P value of LSD & & $\mathrm{P}<0.001^{\mathrm{a}}$ & $\mathrm{P}<0.001^{\mathrm{a}, \mathrm{b}}$ \\
\hline & $\begin{array}{l}\mathrm{r} \text { with serum } \\
\text { adropin }\end{array}$ & & $\mathrm{r}=-0.979, \mathrm{P}<0.001$ & $r=-0.866, P<0.01$ \\
\hline \multirow{3}{*}{$\begin{array}{l}\text { Serum HDL-c } \\
\qquad(\mathrm{mg} / \mathrm{dl})\end{array}$} & $\bar{X} \pm S D$ & $39.99 \pm 3.42$ & $21.95 \pm 5.62$ & $31.14 \pm 4.67$ \\
\hline & P value of LSD & & $\mathrm{P}<0.001^{\mathrm{a}}$ & $\mathrm{P}<0.001^{\mathrm{a},} \mathrm{P}<0.01^{\mathrm{b}}$ \\
\hline & $\begin{array}{l}\mathrm{r} \text { with serum } \\
\text { adropin }\end{array}$ & & $\mathrm{r}=0.911, \mathrm{P}<0.001$ & $\mathrm{r}=0.894, \mathrm{P}<0.001$ \\
\hline \multirow{3}{*}{$\begin{array}{l}\text { Serum LDL-c } \\
\qquad(\mathrm{mg} / \mathrm{dl})\end{array}$} & $\bar{X} \pm S D$ & $22.67 \pm 8.17$ & $119.56 \pm 15.99$ & $61.8184 \pm 14.32$ \\
\hline & $\mathrm{P}$ value of $\mathrm{LSD}$ & & $\mathrm{P}<0.001^{\mathrm{a}}$ & $\mathrm{P}<0.001^{\mathrm{a}, \mathrm{b}}$ \\
\hline & $\begin{array}{l}\mathrm{r} \text { with serum } \\
\text { adropin }\end{array}$ & & $\mathrm{r}=-0.938, \mathrm{P}<0.001$ & $\mathrm{r}=-0.758, \mathrm{P}<0.05$ \\
\hline \multirow{3}{*}{$\begin{array}{l}\text { Serum VLDL-c } \\
\quad(\mathrm{mg} / \mathrm{dl})\end{array}$} & $\bar{X} \pm S D$ & $12.91 \pm 1.76$ & $28.92 \pm 2.47$ & $19.04 \pm 1.64$ \\
\hline & $\mathrm{P}$ value of LSD & & $\mathrm{P}<0.001^{\mathrm{a}}$ & $\mathrm{P}<0.001^{\mathrm{a}, \mathrm{b}}$ \\
\hline & $\begin{array}{l}\text { r with serum } \\
\text { adropin }\end{array}$ & & $\mathrm{r}=-0.979, \mathrm{P}<0.001$ & $r=-0.866, P<0.01$ \\
\hline
\end{tabular}

$a=$ versus group $-1 \quad b=$ versus group-2 
Table (3): Serum TNF- $\alpha$, IL-6 \& PAI-1 and renal MDA levels, SOD, and GSH-Px activities of all studied groups.

\begin{tabular}{|c|c|c|c|c|}
\hline \multicolumn{2}{|c|}{$\mathrm{Parameters}_{\text {Groups }}$ Groups } & \multirow{2}{*}{\begin{tabular}{|c|} 
Group I \\
$48.61 \pm 4.58$
\end{tabular}} & \multirow{2}{*}{$\begin{array}{c}\text { Group II } \\
66.20 \pm 5.15\end{array}$} & \multirow{2}{*}{$\begin{array}{l}\text { Group III } \\
54.44 \pm 3.89\end{array}$} \\
\hline \multirow{3}{*}{$\begin{array}{l}\text { Serum TNF- } \alpha \\
\quad(\mathrm{pg} / \mathrm{ml})\end{array}$} & $\bar{X} \pm S D$ & & & \\
\hline & $P$ value of LSD & & $\mathrm{P}<0.001^{\mathrm{a}}$ & $\mathrm{P}<0.01^{\mathrm{a},} \mathrm{P}<0.001^{\mathrm{b}}$ \\
\hline & $\begin{array}{l}\text { r with serum } \\
\text { adropin }\end{array}$ & & $\mathrm{r}=-0.930, \mathrm{P}<0.001$ & $\mathrm{r}=-0.954, \mathrm{P}<0.001$ \\
\hline \multirow{3}{*}{$\begin{array}{l}\text { Serum IL-6 } \\
(\mathrm{pg} / \mathrm{ml})\end{array}$} & $\bar{X} \pm S D$ & $9.73 \pm 1.32$ & $20.50 \pm 2.53$ & $13.87 \pm 1.59$ \\
\hline & $\mathrm{P}$ value of LSD & & $\mathrm{P}<0.001^{\mathrm{a}}$ & $\mathrm{P}<0.001^{\mathrm{a}, \mathrm{b}}$ \\
\hline & $\begin{array}{l}\text { r with serum } \\
\text { adropin }\end{array}$ & & $\mathrm{r}=-0.901, \mathrm{P}<0.001$ & $\mathrm{r}=-0.836, \mathrm{P}<0.01$ \\
\hline \multirow{3}{*}{$\begin{array}{l}\text { Serum PAI-1 } \\
\quad(\mathrm{ng} / \mathrm{ml})\end{array}$} & $\bar{X} \pm \mathrm{SD}$ & $4.68 \pm 0.53$ & $15.30 \pm 2.59$ & $9.03 \pm 1.42$ \\
\hline & $\mathrm{P}$ value of LSD & & $\mathrm{P}<0.001^{\mathrm{a}}$ & $\mathrm{P}<0.001^{\mathrm{a}, \mathrm{b}}$ \\
\hline & $\begin{array}{l}\text { r with serum } \\
\text { adropin }\end{array}$ & & $\mathrm{r}=-0.776, \mathrm{P}<0.01$ & $\mathrm{r}=-0.821, \mathrm{P}<0.01$ \\
\hline \multirow{3}{*}{$\begin{array}{c}\text { renal } \\
\mathrm{MDA}(\mathrm{nmol} / \mathrm{gm} \\
\text { tissue })\end{array}$} & $\bar{X} \pm \mathrm{SD}$ & $37.27 \pm 3.15$ & $68.89 \pm 5.48$ & $52.07 \pm 4.39$ \\
\hline & $P$ value of LSD & & $\mathrm{P}<0.001^{\mathrm{a}}$ & $\mathrm{P}<0.001^{\mathrm{a}, \mathrm{b}}$ \\
\hline & $\begin{array}{l}\text { r with serum } \\
\text { adropin }\end{array}$ & & $\mathrm{r}=-0.947, \mathrm{P}<0.001$ & $\mathrm{r}=-0.935, \mathrm{P}<0.001$ \\
\hline \multirow{3}{*}{$\begin{array}{c}\text { renal SOD } \\
\text { activity (U/mg } \\
\text { protein) }\end{array}$} & $\bar{X} \pm \mathrm{SD}$ & $10.596 \pm 1.14$ & $6.21 \pm 0.98$ & $9.18 \pm 0.84$ \\
\hline & $\mathrm{P}$ value of LSD & & $\mathrm{P}<0.001^{\mathrm{a}}$ & $\mathrm{P}<0.01^{\mathrm{a},} \mathrm{P}<0.001^{\mathrm{b}}$ \\
\hline & $\begin{array}{l}\text { r with serum } \\
\text { adropin }\end{array}$ & & $\mathrm{r}=0.875, \mathrm{P}<0.01$ & $\mathrm{r}=0.783, \mathrm{P}<0.01$ \\
\hline \multirow{3}{*}{$\begin{array}{c}\text { renal GSH-Px } \\
\text { levels (U/mg } \\
\text { protein) }\end{array}$} & $\bar{X} \pm \mathrm{SD}$ & $13.79 \pm 1.29$ & $9.25 \pm 1.08$ & $12.10 \pm 1.33$ \\
\hline & $P$ value of LSD & & $\mathrm{P}<0.001^{\mathrm{a}}$ & $\mathrm{P}<0.01^{\mathrm{a},} \mathrm{P}<0.001^{\mathrm{b}}$ \\
\hline & $\begin{array}{l}\text { r with serum } \\
\text { adropin }\end{array}$ & & $\mathrm{r}=0.846, \mathrm{P}<0.01$ & $\mathrm{r}=0.735, \mathrm{P}<0.05$ \\
\hline
\end{tabular}

$a=$ versus group $-1 \quad b=$ versus group-2 
Table (4): Serum creatinine, urea, uric acid, angiotensin II, urine flow rate, urine total proteins, urine creatinine concentrations, MABP and GFR of all studied groups.

\begin{tabular}{|c|c|c|c|c|}
\hline $\begin{array}{l}\text { Gro } \\
\text { Parameters }\end{array}$ & & Group I & Group II & Group III \\
\hline & $\bar{X} \pm S D$ & $0.55 \pm 0.06$ & $2.40 \pm 0.37$ & $1.00 \pm 0.14$ \\
\hline Serum creatinine & $\mathrm{P}$ value of LSD & & $\mathrm{P}<0.001^{\mathrm{a}}$ & $\mathrm{P}<0.001^{\mathrm{a}, \mathrm{b}}$ \\
\hline & $\begin{array}{c}\text { r with serum } \\
\text { adropin }\end{array}$ & & $\mathrm{r}=-0.891, \mathrm{P}<0.001$ & $r=-0.787, P<0.01$ \\
\hline & $\bar{X} \pm S D$ & $22.27 \pm 2.41$ & $39.301 \pm 4.62$ & $29.79 \pm 2.23$ \\
\hline Serum urea & $\mathrm{P}$ value of LSD & & $\mathrm{P}<0.001^{\mathrm{a}}$ & $\mathrm{P}<0.001^{\mathrm{a}, \mathrm{b}}$ \\
\hline (mg/dl) & $\begin{array}{c}\text { r with serum } \\
\text { adropin }\end{array}$ & & $\mathrm{r}=-0.950, \mathrm{P}<0.001$ & $\mathrm{r}=-0.835, \mathrm{P}<0.01$ \\
\hline & $\overline{\mathrm{X}} \pm \mathrm{SD}$ & $0.50 \pm 0.05$ & $1.107 \pm 0.21$ & $0.80 \pm 0.07$ \\
\hline Serum uric acid & $\mathrm{P}$ value of LSD & & $\mathrm{P}<0.001^{\mathrm{a}}$ & $\mathrm{P}<0.001^{\mathrm{a}, \mathrm{b}}$ \\
\hline$(\mathrm{mg} / \mathrm{dl})$ & $\begin{array}{c}r \text { with serum } \\
\text { adropin }\end{array}$ & & $\mathrm{r}=-0.921, \mathrm{P}<0.001$ & $\mathrm{r}=-0.892, \mathrm{P}<0.01$ \\
\hline & $\bar{X} \pm S D$ & $9.85 \pm 0.84$ & $15.07 \pm 1.25$ & $11.69 \pm 1.20$ \\
\hline urine flow rate & $\mathrm{P}$ value of LSD & & $\mathrm{P}<0.001^{\mathrm{a}}$ & $\mathrm{P}<0.01^{\mathrm{a},} \mathrm{P}<0.001^{\mathrm{b}}$ \\
\hline$(\mathrm{ml} / 24 \mathrm{~h})$ & $\begin{array}{l}\text { r with serum } \\
\text { adropin }\end{array}$ & & $\mathrm{r}=-0.830, \mathrm{P}<0.001$ & $\mathrm{r}=-0.837, \mathrm{P}<0.01$ \\
\hline & $\bar{X} \pm S D$ & $53.42 \pm 5.51$ & $293.43 \pm 21.16$ & $108.91 \pm 14.36$ \\
\hline $\begin{array}{l}\text { urine total } \\
\text { proteins }\end{array}$ & $\mathrm{P}$ value of LSD & & $\mathrm{P}<0.001^{\mathrm{a}}$ & $\mathrm{P}<0.001^{\mathrm{a}, \mathrm{b}}$ \\
\hline$(\mathrm{mg} / 24 \mathrm{~h})$ & $\begin{array}{c}\text { r with serum } \\
\text { adropin }\end{array}$ & & $\mathrm{r}=-0.950, \mathrm{P}<0.001$ & $r=-0.959, P<0.001$ \\
\hline & $\overline{\mathrm{X}} \pm \mathrm{SD}$ & $124.39 \pm 9.16$ & $92.45 \pm 11.20$ & $105.61 \pm 8.90$ \\
\hline $\begin{array}{l}\text { urine creatinine } \\
\text { concentration }\end{array}$ & $\mathrm{P}$ value of LSD & & $\mathrm{P}<0.001^{\mathrm{a}}$ & $\mathrm{P}<0.001^{\mathrm{a},} \mathrm{P}<0.01^{\mathrm{b}}$ \\
\hline$(\mathrm{mg} / \mathrm{ml})$ & $\begin{array}{l}\mathrm{r} \text { with serum } \\
\text { adropin }\end{array}$ & & $\mathrm{r}=0.964, \mathrm{P}<0.001$ & $\mathrm{r}=0.986, \mathrm{P}<0.001$ \\
\hline & $\bar{X} \pm \mathrm{SD}$ & $1.562 \pm 0.262$ & $0.411 \pm 0.0819$ & $0.865 \pm 0.120$ \\
\hline $\mathrm{GFR}(\mathrm{ml} / \mathrm{min})$ & $\mathrm{P}$ value of LSD & & $\mathrm{P}<0.001^{\mathrm{a}}$ & $\mathrm{P}<0.001^{\mathrm{a}, \mathrm{b}}$ \\
\hline & $\begin{array}{l}\text { r with serum } \\
\text { adropin }\end{array}$ & & $\mathrm{r}=0.881, \mathrm{P}<0.01$ & $\mathrm{r}=0.669, \mathrm{P}<0.05$ \\
\hline & $\bar{X} \pm \mathrm{SD}$ & $92.41 \pm 4.67$ & $134.9 \pm 6.04$ & $115.89 \pm 6.19$ \\
\hline MABP & $\mathrm{P}$ value of LSD & & $\mathrm{P}<0.001^{\mathrm{a}}$ & $\mathrm{P}<0.001^{\mathrm{a}, \mathrm{b}}$ \\
\hline & $\begin{array}{l}\text { r with serum } \\
\text { adropin }\end{array}$ & & $\mathrm{r}=-0.795, \mathrm{P}<0.01$ & $\mathrm{r}=-0.807, \mathrm{P}<0.01$ \\
\hline & $\bar{X} \pm \mathrm{SD}$ & $0.257 \pm 0.031$ & $0.407 \pm 0.052$ & $0.315 \pm 0.036$ \\
\hline $\begin{array}{l}\text { Serum } \\
\text { angiotensin II }\end{array}$ & $\mathrm{P}$ value of LSD & & $\mathrm{P}<0.001^{\mathrm{a}}$ & $\mathrm{P}<0.01^{\mathrm{a},} \mathrm{P}<0.001^{\mathrm{b}}$ \\
\hline (ng/?l) & $\begin{array}{c}\text { r with serum } \\
\text { adropin }\end{array}$ & & $\mathrm{r}=-0.668, \mathrm{P}<0.05$ & $r=-0.641, P<0.05$ \\
\hline
\end{tabular}




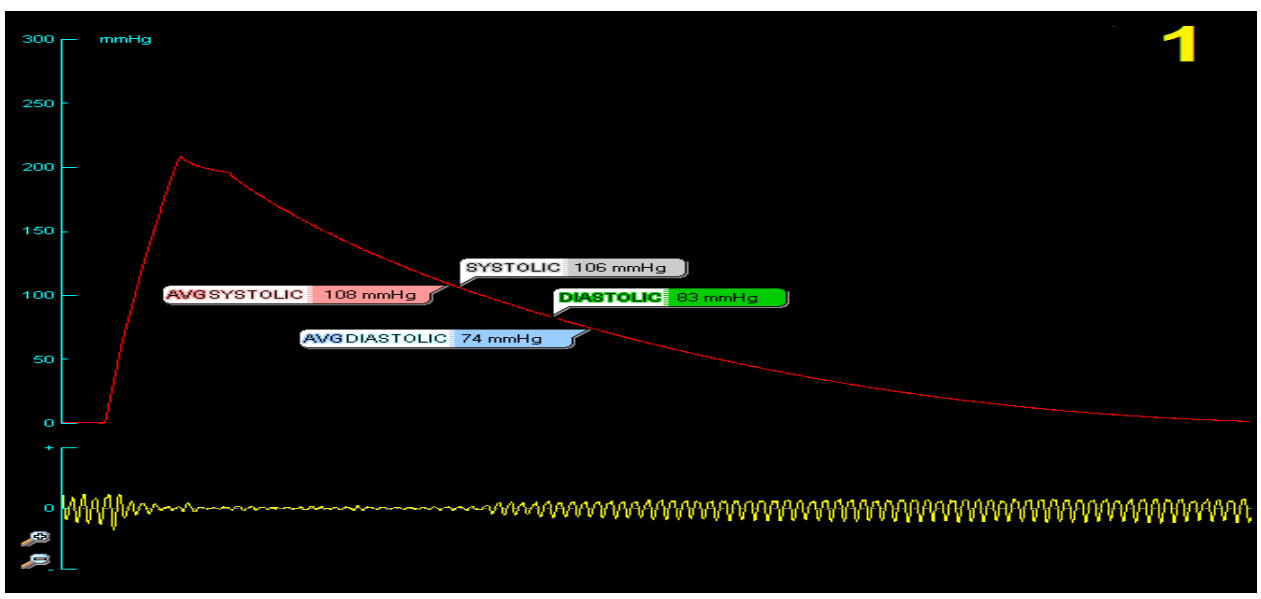

Photo (1): Recorded blood pressure from normal rats

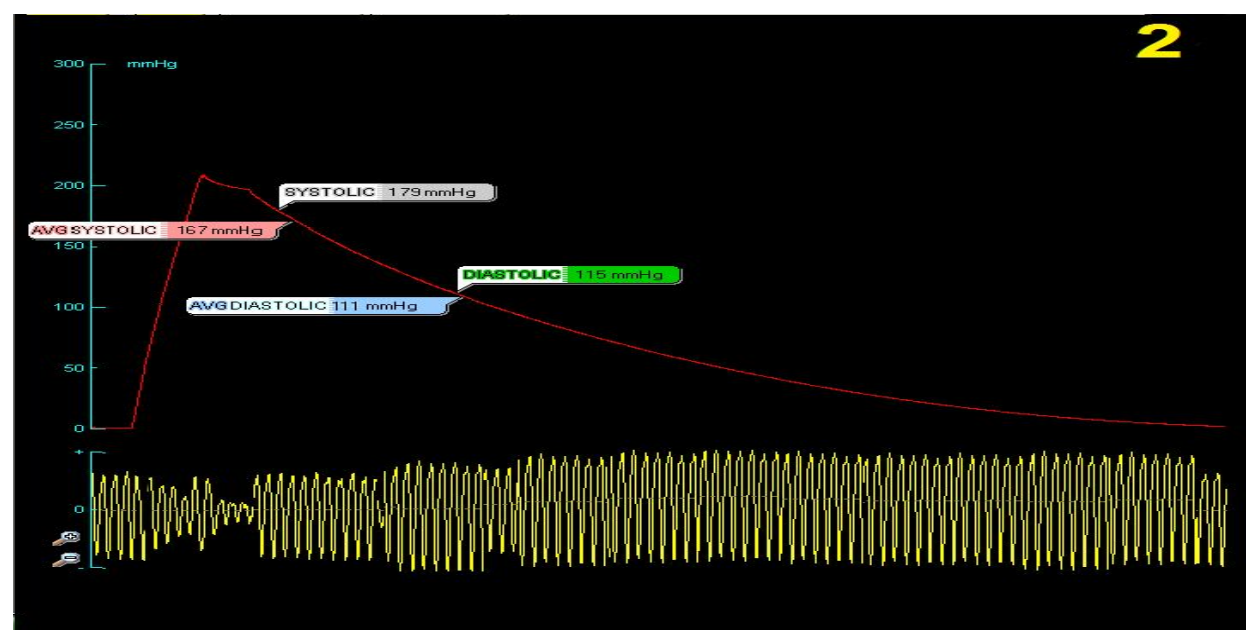

Photo (2): recorded blood pressure from rats in diabetic nephropathy group

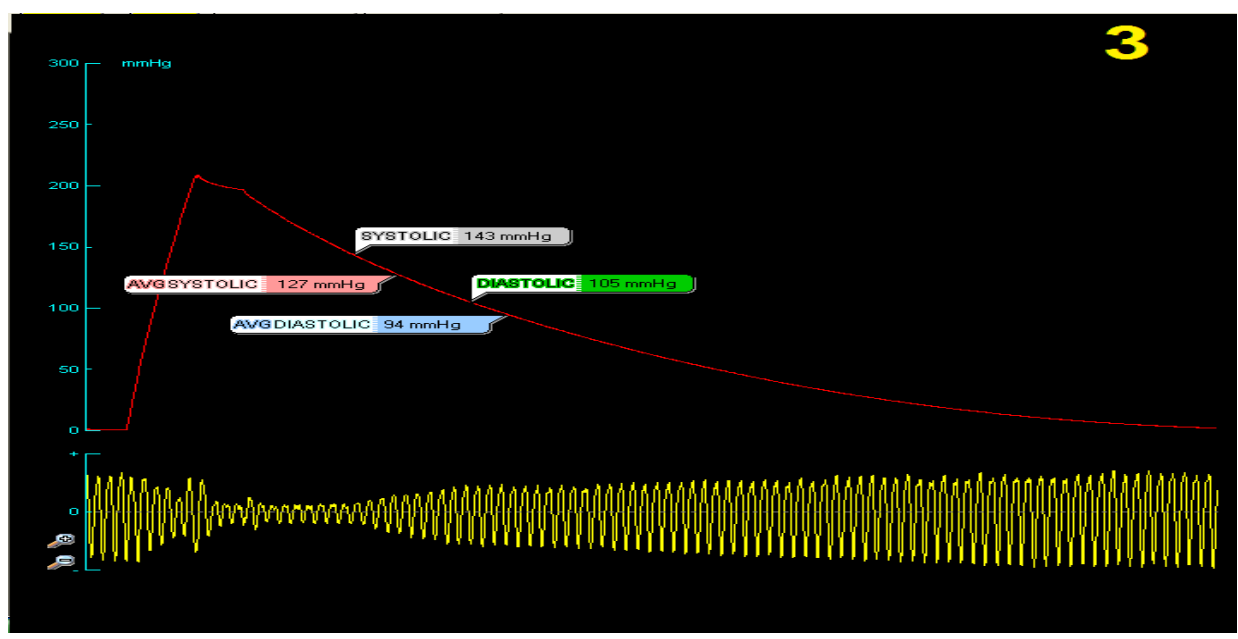

Photos (3): Recorded blood pressure from pioglitazone treated diabetic rats 


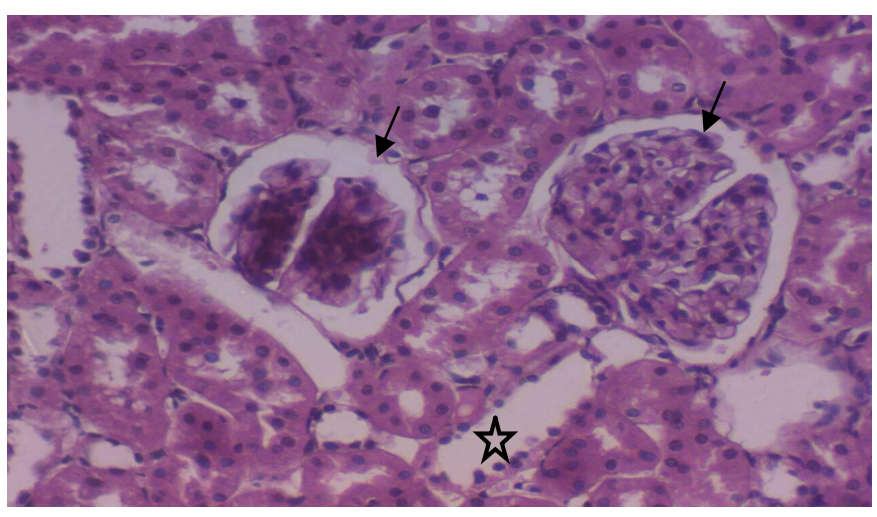

Photo (4): Photomicrograph of kidney tissue of normal control group showing normal renal glomeruli $(\uparrow)$ surrounded by normal renal tubules $\left({ }^{*}\right)$ (H\&E X400).

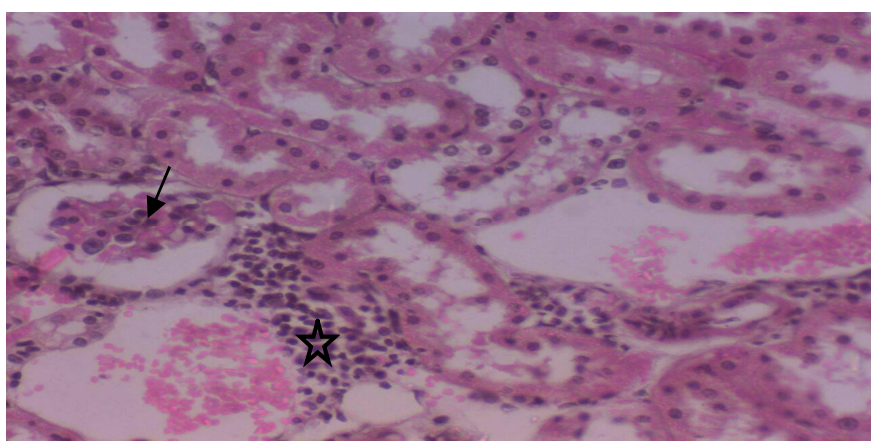

Photo (5): Photomicrograph of kidney tissue of diabetic group showing distorted renal glomeruli $(\uparrow)$, vacuolated renal tubular cells, interstitial hemorrhage and sever cellular infiltration $\left(^{*}\right)$. Apoptotic cells with pyknotic nuclei can also be observed (H\&E X400).

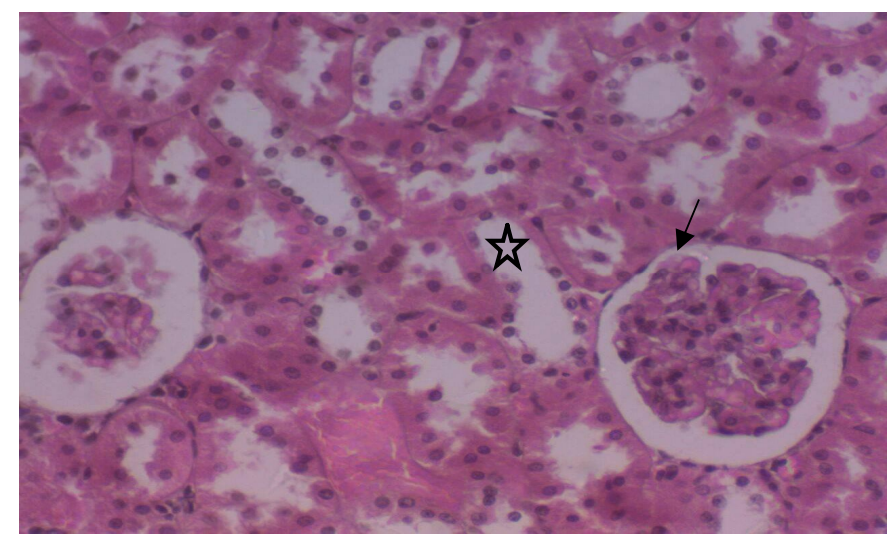

Photo (6): Photomicrograph of kidney tissue of pioglitazone treated diabetic group showing improvement of renal architecture with minimal cellular infiltration and interstitial hemorrhage. Lining epithelium of renal tubules resumes to normal $\left({ }^{*}\right)$. More or less normal glomeruli $(\uparrow)$ were also observed (H\&E X400).

\section{DISCUSSION}

The prevalence of type 2 diabetes mellitus (T2DM) has been increasing worldwide and more than two thirds of the patients may develop diabetic nephropathy (DN) (Xu et al., 2017). Current therapies for DN mainly including hypoglycemic agents and cotreatment with renoprotective drugs are not effective in stopping the progression of $\mathrm{DN}$. Therefore, it is of vital importance and urgency to find more effective therapeutic strategies in countering the diabetesassociated renal injury (Kong et al., 2017).

Treatment with adropin could reduce blood glucose levels and insulin resistance and improve insulin sensitivity in a rat model of T2DM (Akcilar et al., 2016). Also, data regarding serum adropin in T2DM remain conflicting ( $\mathbf{W u}$ et al., 2014 and Ugur et al., 2015). Thus, we 
aimed in this study to examine the effects of pioglitazone on renal functions in type II diabetic rat model and identify the possible mechanisms of action in relation to serum adropin level.

High-dose STZ induced direct nephrotoxicity, making it unable to distinguish between the direct toxic effect of STZ and the lesions that resulted from STZ-induced hyperglycemia (Tay et al., 2005). In other studies, insulin resistance was induced in a rat model via a high-fat diet, followed by a single low dose of STZ to induce hyperglycemia (Srinivasan et al., 2005 and Lee et al., 2013). Elevated glucose levels after 13 weeks successfully induced renal lesions that were similarly present in human patients with DN (Zhang et al., 2017).

T2DM was confirmed in our study by hyperglycemia, hypoinsulinemia, and a significant increase in HOMA-IR index in the diabetic group. Whereas, pioglitazone treatment significantly decreased hyperglycemia and HOMA-IR index in the pioglitazone treated diabetic group when compared to the untreated diabetic one.

Hyperdyslipidemia is also a common symptom of DM (Ma et al., 2014). Significant increases in serum TC, TG, LDL-c and VLDL-c, in addition to a significant decrease in HDL-c were observed in the present work in the diabetic group. On the other hand, pioglitazone was found to significantly lower TC, TG, LDL-c and VLDL-c and significantly increased HDL-c concentrations in the treated diabetic group compared to untreated diabetic one. This was in accordance with the results of Sendrayaperumal et al. (2014) and
Zhang et al. (2014) and. PPAR- $\gamma$ activation by pioglitazone controls a variety of genes involved in different pathways of lipid metabolism such as fatty acid uptake, fatty acid oxidation, lipolysis, and lipoprotein assembly and transport (Grygiel-Gorniak, 2014).

Decreased serum adropin level was also demonstrated in the diabetic rats. However, treatment with pioglitazone significantly increased that level. Moreover, the elevated serum glucose levels, HOMA-IR index, TC, TG, LDL-c and VLDL-c levels were correlated negatively to serum adropin level while the decreased HDL-c was positively correlated with it. This was in agreement with the studies of Kumar et al. (2008) and Akcilar et al., (2016) who also reported that therapy using synthetic adropin or transgenic over expression improves glucose homeostasis and dyslipidemia observed in T2DM. A significant increase in plasma adropin levels was also observed after Roux-en-Y gastric bypass, suggesting that reversal of the metabolic syndrome associated with obesity is also associated with a reversal of low plasma adropin levels (Butler et al., 2012).

However, in contrast to our results, Aydin et al. 2013, Ugur et al. (2015), and Hosseini et al. (2016) reported higher adropin levels in T2DM and argued that to the high glucose levels or a response to the anti-diabetic medications.

The discrepancy between our results and those of others may be due to species differences, duration of diabetes, and / or treatment used.

Moreover, our results revealed significant decreases in the GFR and urine 
creatinine level together with significant increases in serum creatinine, urea, and uric acid levels, urine flow rate and protein in the diabetic group which indicates development of diabetic nephropathy. These results were in accordance with the findings of Zhang et al. (2017), who reported that HFD/STZinduced diabetes affect kidney function parameters after 13 weeks.

In addition, the elevated serum creatinine, urea, uric acid, urine flow rate and protein were correlated negatively to serum adropin level, while the decreased GFR and urine creatinine were positively correlated with circulating adropin level. This was in accordance with the results of Wu et al. (2014) \&Hu and Chen (2016) who reported lower serum adropin concentrations in T2DM patients that were negatively correlated with blood creatinine, and positively correlated with glomerular filtration rate. However, Hu and Chen (2016) reported no significant correlation of serum adropin with dyslipidemia or blood glucose

Histopathological examination in the present study indicated severe damage to the kidney tissue including distorted renal glomeruli, vacuolated renal tubular cells, interstitial hemorrhage, and severe cellular infiltration. Noteworthy, treatment with pioglitazone successfully counteracted these morphological alterations and previous renal function parameters. This was in accordance with the findings of Peng et al. (2014) and Chen et al. (2015) who revealed that treatment with pioglitazone can reduce proteinuria and other manifestations of kidney damage.

Genetic variations that have subtle effects on the activity of gene encoding adropin may confer increased susceptibility to type II diabetes (Kumar et al., 2012). Antidiabetic and hypolipidemic effects of adropin in streoptozotocininduced type 2 diabetic rats have also been previously demonstrated (Akc)ar et al., 2016). Thus, its increase in the pioglitazone treated rats may play a role in the metabolic amelioration seen in that group.

Furthermore, diabetes in our study is associated with a significant reduction in the body weight. In agreement with our resuls, Eissa et al. (2015) reported that (HFD/ STZ) diabetic group showed an increase in body weight followed by acute weight loss after STZ injection. The body weight was progressively reduced due to hyperglycemia, hypoinsulinemia, increased muscle wasting and loss of tissue proteins (Zafar \& Naqvi, 2010 and Cheng et al., 2013).

However, pioglitazone significantly increased the body weight in the treated group compared to diabetic group that may be through the improvement in glucose homeostasis, which was demonstrated in our results. Pioglitazone treatment may also increase feeding since PPAR- $\gamma$ increases feeding by reducing leptin levels, a hormone that regulates satiety center (Brand et al., 2003).

Chronic hyperglycemia results in the accumulation of advanced glycation end products, and increased production of reactive oxygen species (ROS) in renal tissue that plays a crucial role in the development of diabetic nephropathy through affecting lipids, DNA and proteins causing damage to the blood vessels and renal tissue (Cheng et al., 2013 and Sohn et al., 2013). 
In our diabetic rat model, decreased levels of the SOD and GSH-Px activities accompanied by an increase in MDA levels were observed in the kidney tissue. However, treatment with pioglitazone ameliorates those values in the treated group. MDA is a late-stage lipid oxidation byproduct and an important indicator of free radical-induced lipid peroxidation (Cheng et al., 2013).

ROS further stimulates inflammatory cytokine production that serve as chemoattractants for macrophages and $\mathrm{T}$ lymphocytes, and increase apoptosis of podocytes, endothelial and mesangial cells (Bussolati et al., 2005). They also cause increased production of vasoactive substances and reduced production of vasodilators such as prostacyclin and nitric oxide, which results in enhanced vasoconstriction by vasoconstrictors such as angiotensin II and PAI-1. These effects have significant vascular and renal consequences (Keane, 2000).

Our study also found significant increases in serum IL-6, TNF- $\alpha$ and PAI1 , with significant negative correlations versus serum adropin in the diabetic group. In accordance with our results, Kume et al. (2016) reported that circulating adropin level was negatively correlated with TNF- $\alpha$ level in women with polycystic ovarian syndrome. Adropin significantly decreased the mRNA expression levels of TNF- $\alpha$ and IL-6 in the pancreas of diabetic rats and may play a protective role in $\mathrm{DN}$ development through anti-inflammatory effects (Akcilar et al., 2016 \& Hu and Chen, 2016).
Meanwhile, pioglitazone significantly decreased IL-6, TNF- $\alpha$ and PAI-1serum levels in the treated diabetic group compared to untreated diabetic one. A low dose of pioglitazone, unable to normalize glycemia, also counteracts chronic inflammation and oxidative stress by blocking $\mathrm{NF}-\kappa \mathrm{B}$ pathway activation in the diabetic kidney (Ko et al., 2008 and Rizos et al., 2008). In vitro results also demonstrated that pioglitazone reduces glucose induced TGF- $\beta 1$, fibronectin and collagen IV in human proximal tubular cells (Panchapakesan et al., 2005).

Angiotensin II (ANG II) also significantly increased in our study in the diabetic group compared to control, with significant negative correlation versus serum adropin level. This was in agreement with the finding of Al-Qattan et al. (2016) who reported a significant increase in plasma AngII in diabetic rats but at variance with that of Vallon et al. (1995) who reported decreased AngII concentration in diabetes.

In early DM, the concentrations of renal AngII and its receptor AT1 are reduced leading to hyperfiltration (Nankivell, 2001), but an augmented renal angiotensin system activity occurs at later stages of DM when molecular/cellular transformations lead to severe renal injuries; in particular glomerulotubular sclerosis, which impedes kidney clearance function leading to the end-stage renal failure that is characteristic of advanced DM (Siragy et al., 2003).

Hyperglycemia provoked high AngII concentration and stimulation of overexpressed AT1 receptors lead to 
sodium retention, vascular resistance, glomerular capillary pressure, mechanostretch-induced reactive oxygen species production, and tubulointerstitial cell hypertrophy and hyperplasia associated with extracellular mesangial matrix production (Banday and Lokhandwala, 2008).

MABP also significantly elevated in that study in the diabetic rats compared to control, but pioglitazone treatment significantly reduced it in the treated group. The reduction of blood pressure in our study may also have contributed to the renal protective effects of pioglitazone as prolonged systemic hypertension is an important contributor of the endothelial injuries to the kidneys (Nazar, 2014), although the converse process may also occur, e.g. an improvement of blood pressure due to pioglitazone beneficial effects on the kidney (Toblli et al., 2009).

The mechanism of hypertension in diabetic nephropathy includes excess sodium retention, sympathetic nervous system and renin-angiotensin-aldosterone system activation, endothelial cell dysfunction and increased oxidative stress (Van Buren and Toto, 2011). Decreased serum adropin levels are also negatively correlated with the increased blood pressure in our study.

Gu et al. (2015) also noted that adropin had a negative correlation with systolic and diastolic blood pressures in essential hypertension and may be an independent predictor for hypertension and may influence blood pressure by protecting endothelial function via increasing $\mathrm{NO}$ synthase expressions. Moreover, it may be used as a marker indicating endothelial dysfunction in patients with T2DM (Topuz et al., 2013).

\section{CONCLUSION}

Diabetes mellitus is associated with many deviations from normal homeostasis which include metabolic derangements (hyperglycemia and dyslipidemia), oxidative stres, inflammation, hypertension and fibrosis that lead to progression of DN. Moreover, decreased serum adropin level may have a role in the initiation of these effects.

Meanwhile, pioglitazone significantly improved diabetic nephropathy and all of the above mentioned deteriorations predisposing to its progression including the decreased circulating adropin level.

Further studies are required to investigate the use of adropin as a novel potential protective target for diabetic nephropathy.

\section{ACKNOWLEDGMENT}

To Dr. Hanan Lotfy, Pathology Department, Faculty of Medicine, Zagazig University, for performing the histopatholgical study.

\section{REFERENCES}

1. Abe M, Okada K, Kikuchi F and Matsumoto K (2008): Clinical investigation of the effects of pioglitazone on the improvement of insulin resistance and blood pressure in type 2-diabetic patients undergoing hemodialysis. Clin Nephrol., 70: 220-228.

2. Abubakar M, Ukwuani A and Mande $U$ (2015): Antihypertensive activity of Hibiscus Sabdariffa aqueous calyx extract in Albino rats. Sky Journal of Biochemistry Research ., 4(3): $16-20$.

3. Akcilar R, Kocak FE and Simsek H (2016): Antidiabetic and hypolipidemic effects of adropinin streoptozotocin-induced type 2 


\section{EBTESAM M. IBRAHIM and SUZAN M.M. MOURSI}

diabetic rats. Bratislava Medical Journal., 117 (2): 100-105.

4. Al-Qattan K, Thomson M, Jayasree D and Ali M (2016): Garlic Attenuates Plasma and Kidney ACE-1 and AngII Modulations in Early Streptozotocin-Induced Diabetic Rats. Physiol Endocrinol Metab., 284(4): 841-54.

5. Aydin S, Kuloglu T, Aydin S, Eren MN, Yilmaz M and Kalayci M (2013): Expression of adropin in rat brain, cerebellum, kidneys, heart, liver, and pancreas in streptozotocininduced diabetes. Mol Cell Biochem., 380: 73 81.

6. Banday AA and Lokhandwala MF (2008): Oxidative stress-induced renal angiotensin AT1 receptor upregulation causes increased stimulation of sodium transporters and hypertension. American Journal of Physiology-Renal Physiology., 295 (3): 698-706.

7. Barham $D$ and Trinder $P$ (1972): An improved colour reagent for the determination of blood glucose by the oxidase system. Analyst., 97: 142-145.

8. Brand CL, Sturis J, Gotfredsen CF, Fleckner J, Fledelius C and Hansen BF (2003): Dual PPARalpha/gamma activation provides enhanced improvement of insulin sensitivity and glycemic control in ZDF rats. Am J Physiol Endocrinol Metab., 284(4): 841-54.

9. Bussolati B, Deregibus MC, Fonsato V, Doublier S, Spatola T and Procida S (2005): Statins prevent oxidized LDL-induced injury of glomerular podocytes by activating the phosphatidylinositol 3-kinase/AKT-signaling pathway. J Am Soc Nephrol., 16: 1936-47.

10. Butler A, Tam CS, Stanhope KL, Wolfe BM, Ali MR and O'Keeffe M (2012): Low circulating adropin concentrations with obesity and aging correlate with risk factors for metabolic disease and increase after gastric bypass surgery in humans. Journal of Clinical Endocrinology and Metabolism., 97: 3783-91.

11. Chen YH, Chiang MH, Liu JS, Chang YK and Kuo KL (2015): Thiazolidinediones and Risk of Long-Term Dialysis in Diabetic Patients with Advanced Chronic Kidney Disease: A Nationwide Cohort Study. PLOS ONE., 70: 220-228. .

12. Cheng D, Liang $B$ and Li Y (2013): Antihyperglycemic effect of Ginkgo biloba extract in streptozotocin-induced diabetes in rats. Clin Nephrol., 70: 222-230.

13. Cockcroft D and Gault M (1976): Prediction of creatinine clearance from serum creatinine. Nephron,, 16(1): 31-41.
14. Danda RS, Habiba NM, Rincon-Choles H, Bhandari BK, Barnes JL, Abboud HE and Pergola PE (2005): Kidney involvement in a nongenetic rat model of type 2 diabetes. Kidney international., 68(6): 2562-71.

15. Drury $R$ and Wallington $E$ (1980): Preparation and fixation of tissues. In: Drury RAB, Wallington EA, editors. Carleton's Histological Technique. Journal of Clinical Endocrinology and Metabolism., 96: 3782-91.

16. Eissa LA, Abdel-Rahman Nand Eraky SM (2015): Effects of omega-3 fatty acids and pioglitazone combination on insulin resistance through fibroblast growth factor 21 in type 2 diabetes mellitus. Egyptian Journal of Basic and Applied Sciences., 2: 75-86.

17. Engvall E and Perlmann P (1971): Enzymelinked immunosorbent assay (ELISA). Quantitative assay of immunoglobulin G. Immunochemistry, 8(9): 871-874, 1971.

18. Fernando B, Marley R, Holt S, Anand R and Harry $D$ (1998): N-acetylcysteine prevents development of the hyperdynamicciculation in the portal hypertensive rat. Hepatology, 28(3):689-692.

19. Forbes JM, Coughlan MT and Cooper ME (2008): Oxidative stress as a major culprit in kidney disease in diabetes. Diabetes., 57: 14461454.

20. Friedewald W, Levy $R$ and Fredrickson $D$ (1972): Estimation of the concentration of lowdensity lipoprotein cholesterol in plasma, without use of the preparative ultracentrifuge. Clin Chem., 18:499-502.

21. Grygiel-Gorniak B (2014): Peroxisome proliferator-activated receptors and their ligands: nutritional and clinical implications a review. Nutr J., 4(289):13-17

22. Gu X, Li H, Zhu X, Gu H, Chen J, Wang L, Harding $P$ and $X u$ W (2015): Inverse Correlation Between Plasma Adropin and ET-1 Levels in Essential Hypertension: A CrossSectional Study. Medicine (Baltimore), 94(40): 1712-1754.

23. Hosseini A, Shanaki M, Emamgholipour S, Nakhjavani $M, \quad$ Razi $F$ and Golmohammadi T (2016): Elevated Serum Levels of Adropin in Patients with Type 2 Diabetes Mellitus and its Association with Insulin Resistance. Journal of Biology and Today's World., 5: (3): 44-49.

24. Hu W and Chen $L$ (2016): association of serum adropin concentrations with diabetic nephropathy. Mediators of Inflammation., 18:499-502. 
25. Jaffé M (1986): On the precipitate which produces picric acid in normal urine and on a new reaction of creatinine. $\mathrm{Z}$ Physiol Chem., 10: 391-400.

26. Jones R, Dilks $R$ and Nowell $N$ (1973): A method for the collection of individual mouse urine. Physiology and Behavior., 10: 163-164.

27. Kakkar P, Das B and Viswanathan P.N. (1984): A modified spectrophotometric assay of superoxide dismutase. Indian J. Biochem. Biophys., 21: 130- 132.

28. Keane WF (2000): The role of lipids in renal disease: Future challenges. Kidney Int Suppl., 75: 27-31.

29. Ko GJ, Kang YS, Han SY, Lee MH, Song HK, Han KH, Kim HK, Han JY and Cha DR (2008): Pioglitazone attenuates diabetic nephropathy through an anti-inflammatory mechanism in type 2 diabetic rats. Clinical Endocrinology and Metabolism., 23(9): 275060.

30. Kong L, Wang Y, Luo M, Tan Y, Cui W and Miao $L$ (2017): Prevention of Streptozotocin-Induced Diabetic Nephropathy by MG132: Possible Roles of $\mathrm{Nrf2}$ and $\mathrm{I} \kappa \mathrm{B}$. Oxidative Medicine and Cellular Longevity., 28(3):689-692.

31. Kumar K, Sharma S, Vashishtha V, Bhardwaj P, Kumar A, Barhwal $K$ and Singh B (2016): Terminalia arjuna bark extract improves diuresis and attenuates acute hypobaric hypoxia induced cerebral vascular leakage. J Ethnopharmacol., 180:43-53.

32. Kumar K, Zhang J, Gao S, Rossi J, McGuinness O, Halem H, Culler M, Mynatt $R$ and Butler A (2012): Adropin deficiency is associated with increased adiposity and insulin resistance. Obesity (Silver Spring),, 20(7): 1394-1402.

33. Kumar KG, Trevaskis JL, Lam DD, Sutton GM, Koza RA and Chouljenko VN (2008): Identification of adropin as a secreted factor linking dietary macronutrient intake with energy homeostasis and lipid metabolism. Cell Metab., 8: 468-481.

34. Kume T, Calan M and Yilmaz O (2016): A possible connection between tumor necrosis factor alpha and adropin levels in polycystic ovary syndrome. Journal of Endocrinological Investigation., 39 (7): 747-754.

35. Lee KM, Yang SJ, Kim YD, Choi YD, Nam JH, Choi CS, Choi HS and Park CS (2013): Disruption of the cereblon gene enhances hepatic AMPK activity and prevents high-fat diet-induced obesity and insulin resistance in mice. Diabetes., 62(6):1855-64.

36. Ma Y, Wang Y, Huang $Q$, Ren $Q$, Chen $S$, Zhang A, Zhao $L$, Zhen $Q$ and Peng $Y$ (2014): Impaired $\beta$ cell function in Chinese newly diagnosed type 2 diabetes mellitus with hyperlipidemia. J Diabetes., 62(6):1855-64.

37. Matthews D, Hosker J, Rudenski A, Naylor B, Treacher D and Turner R (1985): Homeostasis model assessment: insulin resistance and beta-cell function from fasting plasma glucose and insulin concentrations in man. Diabetologia., 28: 412-419.

38. Nankivell BJ (2001): Creatinine clearance and the assessment of renal function. Australian Prescriber., 24 (1): 15-17.

39. Nazar CMJ (2014): Mechanism of hypertension in diabetic nephropathy. Journal of Nephropharmacology, 3(2):49-55.

40. Nishi $H$ and Elin $R$ (1985): Three turbidimetric methods for determining total protein compared. Clin Chem., 31: 1377-1380.

41. Novelli E, Diniz Y, Galhardi C, Ebaid G, Rodrigues $H$ and Mani F (2007): Anthropometrical parameters and markers of obesity in rats. Lab Anim., 41(1):111-119.

42. Ohkawa H, Ohishi N and Yagi K. (1979): Assay for lipid peroxides in animals and tissue by thiobarbituric acid reaction. Anal. Biochem., 95: 351-358.

43. Panchapakesan U, Sumual $S$ and Pollock CA (2005): PPAR gamma agonists exert antifibrotic effects in renal tubular cells exposed to high glucose. Am J Physiol Renal Physiol., 289: F1153-F1158.

44. Peng XH, Liang PY, Ou SJ and Zu XB (2014): Protective effect of pioglitazone on kidney injury in diabetic rats. Asian Pac J Trop Med., 7(10): 819-22.

45. Qian Y, Feldman E and Pennathur S (2008): From fibrosis to sclerosis: mechanisms of glomerulosclerosis in diabetic nephropathy. Diabetes., 57: 1439-1445.

46. Reddy K.P, Subhani S.M, Khan P.A and Kumar K.B. (1995): Effect of light and benzyl adenine on dark-treated growing rice leaves, II changes in peroxidase activity. Plant Cell Physiol., 24: 987-994.

47. Rizos CV, Liberopoulos EN and Mikhailidis DP (2008): Pleiotropic effects of thiazolidinediones. Expert Opin Pharmacother., 9: 10871108.

48. Sarafidis PA (2008): Obesity, insulin resistance and kidney disease risk: insights into 


\section{EBTESAM M. IBRAHIM and SUZAN M.M. MOURSI}

the relationship. Curr Opin Nephrol Hypertens., 17: 450-456.

49. Sendrayaperumal V, Iyyam Pillai S and Subramanian S (2014): Design, synthesis and characterization of zinc-morin, a metal flavonol complex and evaluation of its antidiabetic potential in HFD-STZ induced type 2 diabetes in rats. Chem Biol Interact., 219 (5): 9-17.

50. Siragy HM, Awad A, Abadir P and Webb R (2003): The angiotensin II type 1 receptor mediates renal interstitial content of tumor necrosis factor- $\alpha$ in diabetic rats. Endocrinology., 144 (6): 2229-2233.

51. Sohn E, Kim J and Kim C (2013): The extract of Litsea japonica reduced the development of diabetic nephropathy via the inhibition of advanced glycation end products accumulation in $\mathrm{db} / \mathrm{db}$ mice. Diabetologia, 29: 412-419.

52. Srinivasan K, Viswanad B, Asrat L, Kaul CL and Ramarao P (2005): Combination of high-fat diet-fed and low-dose streptozotocintreated rat: a model for type 2 diabetes and pharmacological screening. Pharmacol Res., 52: 313-320.

53. Tanios BYand Ziyadeh FN (2012): Emerging therapies for diabetic nephropathy patients: beyond blockade of the renin-angiotensin system. Nephron Extra., 2: 278-282.

54. Tay YC, Wang Y, Kairaitis L, Rangan GK, Zhang $C$ and Harris DC (2005): Can murine diabetic nephropathy be separated from superimposed acute renal failure? Kidney Int., 68(1): 391-8.

55. Temple R, Clark $P$ and Hales $C$ (1992): Measurement of insulin secretion in type 2 diabetes: problems and pitfalls. Diabetic Medicine., 9: 503-512.

56. Tietz N (1990): Clinical Guide to laboratory Tests, 2nd edition. Am J Physiol Renal Physiol., 289: 1154-1159.

57. Tietz N (1995): Clinical guide to laboratory tests, 3rd edition. Lab Anim., 40(8):111-119.

58. Toblli JE, Ferrini MG, Cao G, Vernet D, Angerosa $M$ and Gonzalez-Cadavid NF (2009): Antifibrotic effects of pioglitazone on the kidney in a rat model of type 2 diabetes mellitus. Nephrol Dial Transplant., 24: 2384 2391.

59. Topuz M, Celik A, Aslantas T, Demir AK, Aydin S and Aydin S (2013): Plasma adropin levels predict endothelial dysfunction like flow mediated dilatation in patients with type 2 diabetes mellitus. J Investig Med., 61: 11611164

60. Ugur K, Oz B, Ozkan Y, Sener SY, Orhan B and Aydin S (2015): Microalbuminuria by concentration serum and urine levels of adropin in patients with type 2 diabetes mellitus. Nephron Extra., 2: 278-282.

61. Vallon V, Wead LM and Blantz RC (1995): Renal hemodynamics and plasma and kidney angiotensin II in established diabetes mellitus in rats: effect of sodium and salt restriction. Journal of the American Society of Nephrology., 5 (10): 1761-1767.

62. Van Buren $P N$ and Toto $R$ (2011): Hypertension in Diabetic Nephropathy: Epidemiology, Mechanisms, and Management. Advances in Chronic Kidney Disease; 18(1):2841.

63. Wu L, Fang J, Chen L, Zhao Z, Luo Y, Lin $C$ and Fan $L$ (2014): Low serum adropin is associated with coronary atherosclerosis in type 2 diabetic and non-diabetic patients., Clin Chem Lab Med., 52 (5): 751-758.

64. Xu Y, Bai L, Chen X, Li Y, Qin Y, Meng X and Zhang $Q$ (2017): 6-Shogaol ameliorates diabetic nephropathy through anti-inflammatory, hyperlipidemic, anti-oxidative activity in db/db mice.Biomed Pharmacother., 97:633-641.

65. Yang $\mathrm{C}$, Demars $\mathrm{KM}$, Hawkins KE, Candilario E (2016): Adropin reduces paracellular permeability of rat brain endothelial cells exposed to ischemia-like conditions. Peptides., 81:29-37.

66. Zafar $M$ and Naqvi SN (2010): Effects of STZ-induced diabetes on the relative weights of kidney, liver and pancreas in albino rats: a comparative study. Int J Morphol., 28: 135142.

67. Zhang S, Xu H, Yu X, Wu Y and Sui D (2017): Metformin ameliorates diabetic nephropathy in a rat model of low-dose streptozotocin-induced diabetes. Experimental and Therapeutic Medicine., 14(1): 383-390.

68. Zhang XJ, Deng YX, Shi QZ, He MY, Chen $B$ and Qiu XM (2014): Hypolipidemic effect of the Chinese polyherbal Huanglian Jiedu decoction in type 2 diabetic rats and its possible mechanism. Phytomedicine., 21 (5): 615-623. 


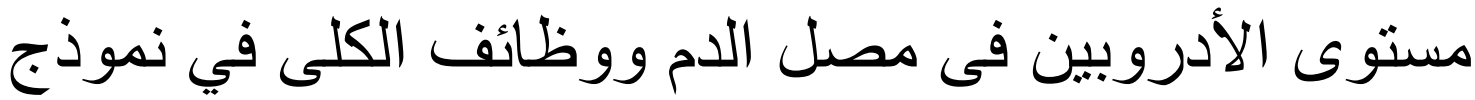

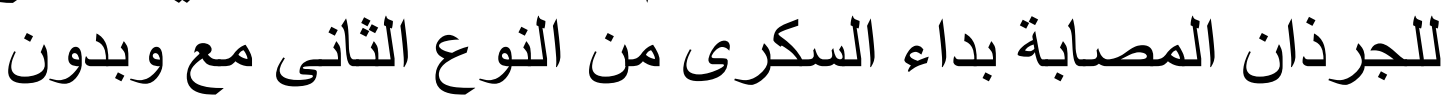 العلاج ببيوجليتازون}

إبتسام محمد إبراهيم - سوزان محمد محمد مرسى

قسم الفسيولوجيا الطبية ، كلية الطب البشرى ، جامعة الزقازيق

خلفية البحث: يعد اعتلال الكلية السكري هو السبب الأكثر شيوعا لتدهور الكلى والوفاة في مرضى السكر، كما أن العلاج بثيازوليدينديون خاصة ببيوجليتازون قد يؤدي إلى تحسن هذا التدهور. علاوة على ذلك، هناك العديد من الهرمونات التى تشارك في الحفاظ على التوازن الأبضي بما في ذللك الأدروبين المكتشف مؤخر ا. ولكن لا تز ال البيانات المتعلقة بمستويات الأدروبين في النوع الثاني من داء السكري متضناربة.

الهدف من البحث : تحديد تأثير بيوجليتازون على بعض معاملات التمثيل الغذائي ووظائف لكلى في نموذج للجرذان المصابة بداء السكرى من النوع الثانى ، ودر اسة العلاقة بين مستوى الأدروبين فى مئي مصل الدم وهذه المعاملات.

مواد وطرق البحث: تم إجر اء هذه الدر اسة على ثلاثين من ذكور الجرذان البيضـاء البالغـة التي يبلغ

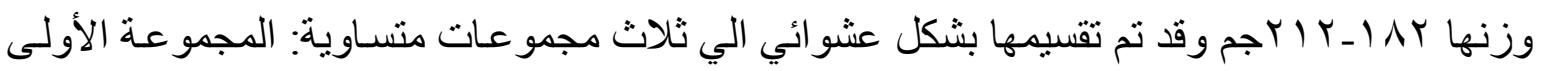
التى إستخدمت كمجموعة ضابطة ، و المجموعة الثانية هى المصابة بداء السكرى من النوع الثانى ، و المجمو عـة الثالثـة هـى المصـابة بـداء السـكرى مـن النـوع الثـانى و المعالجـة ببيوجليتـازون لمـدة ساء أسبوع.

في نهاية فترة التجربة تم قياس وزن الجرذان وحساب مؤشر الكتلة ومتوسط ضغط الدم ومستوى أدروبين و السكر وهرمون الأنسولين ومقاومة الإنسولين في الدم ومستوى الكولسترول الكلي ، الدهون الثثلاثية والبروتين الدهني منخفض الكثافة جدا ومنخفض الكثافة وعالي الكثافة ومستوى انترلوكين 7 ومعامل نخر الورم الفا، و مانع منشط البلازمينوجين- ا ومستوى الكرياتينين و اليوريا وحامض اليوريك ومستوى أنجيوتتسين-r فى مصل الدم. كما تم قياس معدل تدفق البول وقياس مستوى البروتين و الكرياتينين به ومعدل الترشيح الكبيبي باستعمال تركيز الكرياتينين في كل 
من مصل الدم والبول. كما تم عزل الكلى وتحضير أنسجتها للاراسة الميكروسكوبية وقياس مستوى

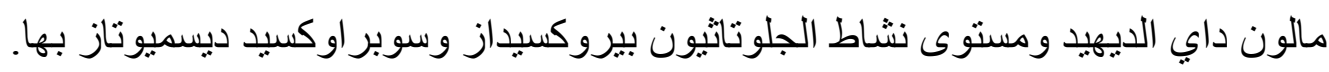
النتائج: أدي داء السكري إلى نقص فى تركيز الأدروبين في الدم. كما أدى إلى زيادة ذات دلالة

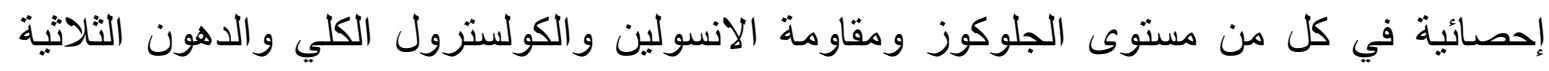

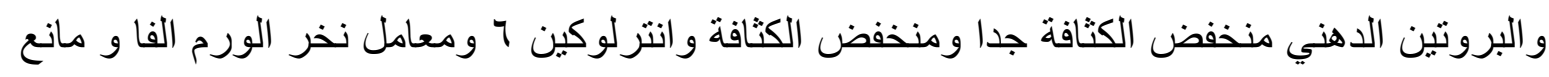

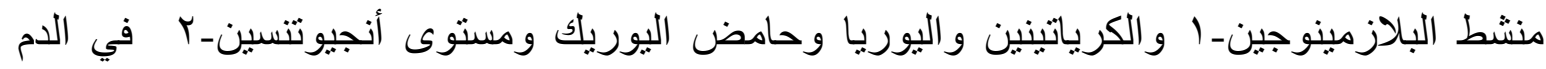

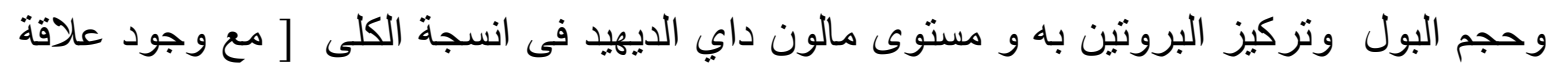

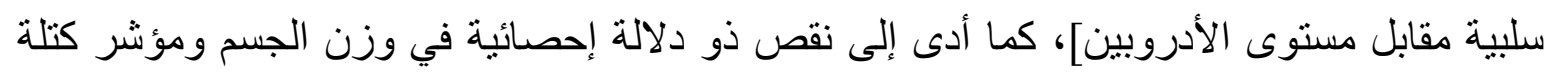

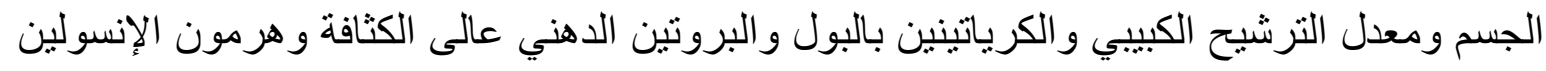

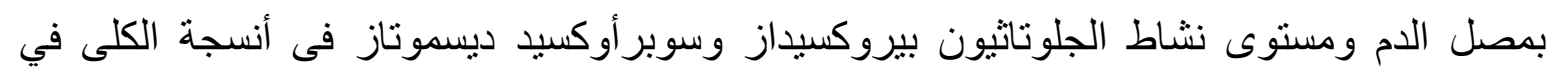

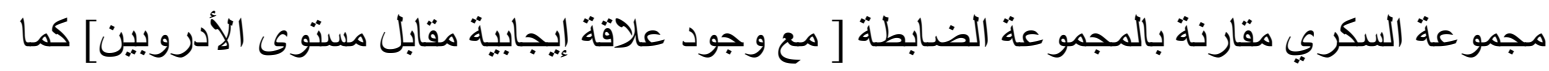

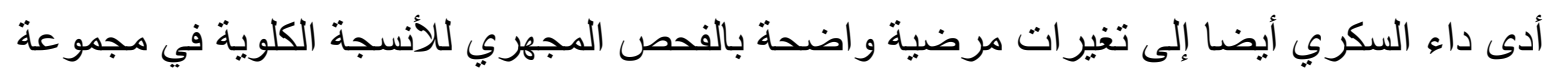

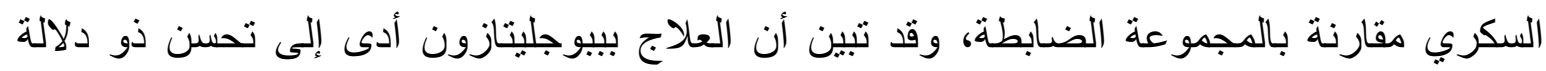
إحصائية فى المعاملات المذكورة أعلاه في مجمو عة السكري المعالجة.

الإستنتاج: تركيز الأدروبين في مصل الدم يرتبط سلبا بالتدهور الكلوي، وقد يكون لـه دور وقائي بالإضافة إلى التحسن بييوجليتازون ضد إعندال الادرولين الكلية السكري. 